\title{
Prevalence and associated factors of persistent diarrhoea in Iranian children admitted to a paediatric hospital
}

\author{
N.A. Kermani, ${ }^{1}$ F. Jafari, ${ }^{1}$ H.N. Mojarad, ${ }^{1}$ N. Hoseinkhan ${ }^{7}$ and M.R. Zali ${ }^{1}$
}

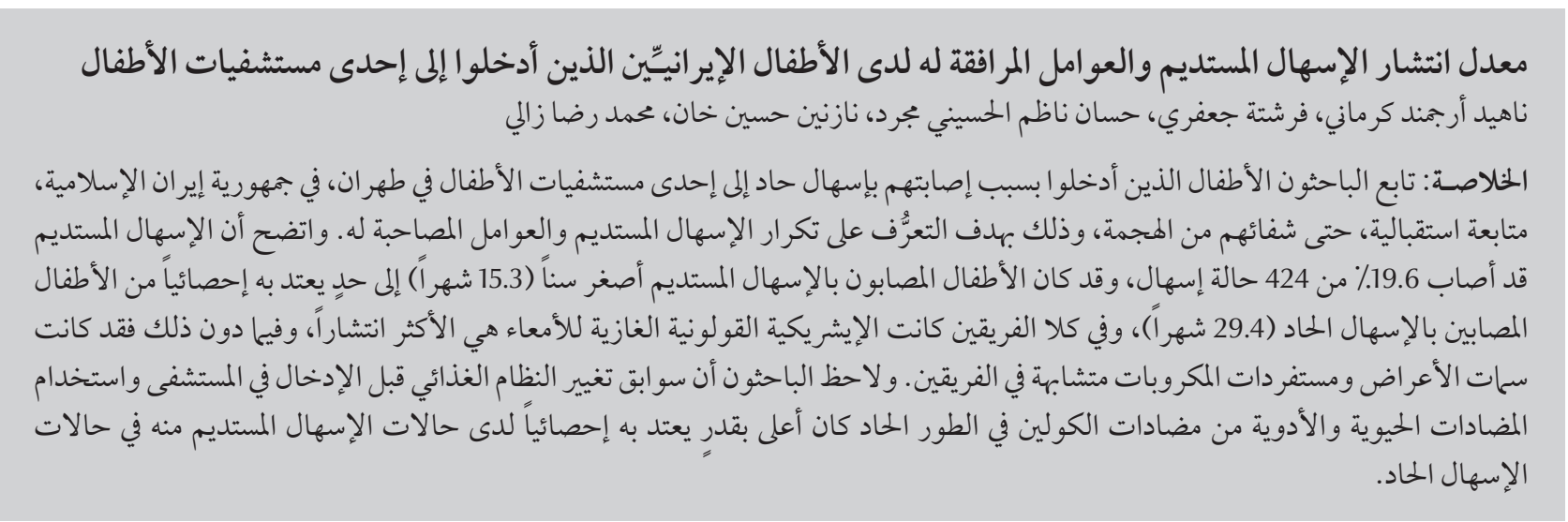

ABSTRACT To identify the frequency and associated factors of persistent diarrhoea in a paediatric hospital in Tehran, Islamic Republic of Iran, children admitted with acute diarrhoea were followed prospectively until resolution of the episode. Persistent diarrhoea developed in 19.6\% of the 424 diarrhoea cases. Children with persistent diarrhoea were significantly younger than those with acute diarrhoea (15.3 versus 29.4 months). Enteroaggregative Escherichia coli was the most prevalent pathogen in both groups, but otherwise the profile of symptoms and isolated organisms was similar in the 2 groups. History of dietary change prior to admission and use of antibiotics and anticholinergic drugs in the acute phase were significantly higher in the persistent than acute diarrhoea cases.

Prévalence et risques associés de diarrhée persistante chez des enfants iraniens consultant en hôpital pédiatrique

RÉSUMÉ Afin d'identifier la fréquence de la diarrhée persistante, et les facteurs associés, au sein d'un hôpital pédiatrique de Téhéran (République islamique d'Iran), des enfants hospitalisés souffrant de diarrhée aiguë ont fait l'objet d'un suivi prospectif jusqu'à résolution de l'épisode. Une diarrhée persistante est apparue dans 19,6 \% des 424 cas de diarrhée. Les enfants souffrant de diarrhée persistante étaient nettement plus jeunes que ceux atteints de diarrhée aiguë $(15,3$ mois contre 29,4$)$. Dans les deux groupes, I'agent pathogène ayant la plus forte prévalence était Escherichia coli entéroaggrégatif. En revanche, le profil des symptômes et des organismes isolés était similaire dans les deux groupes. Les antécédents de changement de régime alimentaire précédant I'hospitalisation et l'utilisation d'antibiotiques et d'anticholinergiques lors de la phase aiguë étaient sensiblement plus élevés dans les cas de diarrhée persistante que dans les cas de diarrhée aiguë.

${ }^{7}$ Research Centre for Gastroenterology and Liver Diseases, Shahid Beheshti University, Tehran, Islamic Republic of Iran (Correspondence to N.A. Kermani:nahid_arjmand_k@yahoo.com\&arjmand_k@irimc.org).

Received: 01/08/08; accepted: 09/11/08 


\section{Introduction}

Diarrhoea is still an important cause of child morbidity and mortality, causing about 2.2 million deaths annually in the paediatric population [1]. With recent improvements in rehydration therapy programmes, a decline has been observed in deaths associated with acute watery diarrhoea, and thus the problem of persistent diarrhoea has become more concerning. Persistent diarrhoea-defined by the World Health Organization as a diarrhoeal episode with an acute onset and a presumptive infectious etiology lasting $\geq 14$ days - comprises only 3\%-20\% of diarrhoea episodes, but up to $50 \%$ of diarrhoea-related deaths [2]. Persistent diarrhoea also imposes a heavy economic burden on low socioeconomic status countries with its devastating effects on nutritional status, growth and development of children $[3,4]$.

There is little information about persistent diarrhoea in the Islamic Republic of Iran. A 7.7\% prevalence was reported in a study from the west of the country, and young age, non-breastfeeding, use of antibiotics and presence of mucoid or bloody diarrhoea were factors associated with it [5]. These factors, in addition to malnutrition, were also observed in other studies of Iranian children $[6,7]$. We conducted the present study to identify the pattern and etiology of persistent diarrhoea among children admitted a paediatric hospital in Tehran and to compare these cases with cases of acute diarrhoea.

\section{Methods}

A cross-sectional prospective study was performed from June 2006 to June 2007 in Mofid Paediatric Hospital, a university-associated referral hospital in Tehran.

\section{Sample size}

Estimated sample size was approximately 400 , considering the $7.7 \%$ prevalence of persistent diarrhoea in Iranian children reported in a study with a similar methodology [5], and 95\% confidence level and $2.5 \%$ acceptable error.

\section{Patients}

The study population was all children below 12 years of age who were admitted for acute diarrhoea during the study period. Previously diagnosed cases of inflammatory bowel disease, coeliac disease and cystic fibrosis were excluded. Also children whose parents were not willing to take part in the study were excluded. Finally, 537 data collection forms were completed. As we were not able to follow up 113 patients due to missing or incorrect contact details or non-response, 424 data collection forms were available for analysis.

\section{Data collection}

Data were collected from the child's medical record and an interview with the parents. Trained nurses visited all the children admitted to the hospital with gastroenteritis. After a brief explanation of the study to one of the parents and acquiring verbal informed consent, a data collection form was completed. This included the demographic characteristics of the child and the episode of diarrhoea (duration, signs and symptoms, changes in diet and any drugs used during the episode).

Diarrhoea was defined as the passage of at least 3 non-bloody stools or 1 bloody loose stool per 24 hours. For exclusively breastfed infants, increased frequency or decreased consistency of stool compared with the previous bowel habit of the infant and noticeable by the mother was considered diarrhoea. The duration of the episode of diarrhoea was calculated from the onset of the disease as stated by the parents. Cases were defined as persistent diarrhoea (duration $\geq 14$ days) or acute diarrhoea (duration $<14$ days).

The child's body weight was measured after rehydration. Weightfor-age $z$-score was calculated using Epi- info, version 6.01, based on the National Centerfor Health Statistics (NCHS) tables and was used to categorize the cases as normal weight ( $\mathrm{z}$-score $\geq-1.0)$, mild underweight $(-1.0<\mathrm{z}$-score $\leq-2.0)$, moderate underweight $(-2.0<\mathrm{z}$-score $\leq-3.0)$ and severe underweight ( $\mathrm{z}$ score $<-3.0$ ). We analysed nutritional status based on weight-for-age z-score score (to avoid bias, we disregarded height-for-age and weight-for-height scores since we observed mistakes during height measurements).

The patients were followed up until resolution of the diarrhoea episode, even if they were discharged from hospital.

\section{Laboratory methods}

A fresh stool specimen was obtained for laboratory testing during the initial days of the diarrhoea. Each specimen was first examined by a light microscope. Asaline and iodine wet-mount preparation was used for detection of amoebae species, Giardia lamblia and Blastocystis hominis, and a formol-ether concentration method for cysts. Trichrome staining and polymerase chain reaction (PCR) was performed to differentiate Entamoeba histolytica/dispar complex from other non-pathogenic intestinal amoeba and E. histolytica from E. dispar respectively. In order to distinguish Cryptosporidium spp., Cyclospora spp. and Isospora belli, a Ziehl-Neelsen acid-fast stained slide was prepared. We used modified trichrome stain for Microsporidium spp.

Bacterial cultures were done on MacConkey and xylose-lysinedeoxycholate agar plates for Salmonella spp., Shigella spp. and diarrheogenic Escherichia coli. PCR was used to detect isolates that carried the eae and $b f p$ genes for enteropathogenic E. coli (EPEC), pCVD432 plasmid for enteroaggregative E. coli (EAEC), heat-labile (LT) and heat-stable (ST) genes of enterotoxigenic E. coli (ETEC), stx 1 and stx2 genes for Shiga-toxin-producing E. coli (STEC), ial and ipaH genes for enteroinvasive E. coli (EIEC) and Shigella spp., and invA gene for Salmonella spp. 


\section{Statistical analysis}

For comparison of proportions between acute and persistent diarrhoea cases, the $\chi^{2}$ or Fisher exact tests were used and for comparison of means the Student $t$-test was used. We considered a $P$-value $<0.05$ as statistically significant. Data were analysed using SPSS, version 13.0.

\section{Results}

\section{Patient characteristics}

A total of 424 children were enrolled in the study. Persistent diarrhoea developed in 83 (19.6\%) cases, both hospitalized and discharged patients. The mean age of the study population was 26.6 months, and $57.3 \%$ of the patients were male. The prevalence of persistent diarrhoea reached $24.4 \%$ in the 291 children aged $<2$ years and $21.8 \%$ in the 372 aged $<5$ years. The male to female ratio was not significantly different between the acute diarrhoea and persistent diarrhoea group (1.4:1 and $1.1: 1$, respectively). More than $80 \%$ of the persistent diarrhoea cases were aged $<18$ months. The mean age in the persistent diarrhoea group was 15.3 months compared with 29.4 months in the acute diarrhoea group $(P<0.001)$. There was also a significant difference in mean age between the 2 groups, when we considered children $<2$ years: 12.1 months in the 220 acute diarrhoea cases versus 9.5 months in the 71 persistent diarrhoea cases $(P=0.002)$.

\section{Symptoms and characteristics of the diarrhoeal episodes}

The mean duration of the diarrhoea episode in the acute diarrhoea group was 5.9 (SD 2.7) days; median 6 days, and in the persistent diarrhoea group 24.9 (SD 18.6) days, median 19 days.

Data regarding related symptoms and some characteristics of the diarrhoeal episodes are summarized in Table 1. Among the symptoms related to diarrhoeal diseases (abdominal pain, nausea and vomiting, loss of appetite and fever) only fever was significantly different between the 2 groups (86.2\% in the acute versus $74.7 \%$ in the persistent diarrhoea group). Defecation times per 24 hours and frequency of bloody or mucoid stool (which may indicate severity of the disease) were not statistically significant between the groups.

The frequency of concurrent diseases, including other infections and immunodeficiency and gastrointestinal disorders, was similar in acute diarrhoea and persistent diarrhoea cases $(21.4 \%$ and $20.5 \%$, respectively $P=0.853$ ) (Table 1). A history of major diet change (i.e. introducing complementary food or animal milk, changing the formula brand or introducing wheat to the child) 2 weeks prior to admission was found in $10.6 \%$ of acute diarrhoea and $20.5 \%$ of persistent diarrhoea cases $(P=0.014)$.

\begin{tabular}{|c|c|c|c|c|c|}
\hline \multirow[t]{2}{*}{ Symptoms and characteristics } & \multicolumn{2}{|c|}{$\begin{array}{l}\text { Acute diarrhoea } \\
\qquad(n=341)\end{array}$} & \multicolumn{2}{|c|}{$\begin{array}{l}\text { Persistent diarrhoea } \\
\qquad(n=83)\end{array}$} & \multirow[t]{2}{*}{$P$-value } \\
\hline & No. & $\%$ & No. & $\%$ & \\
\hline Mean (SD) age (months) & \multicolumn{2}{|c|}{$29.4(29.6)$} & \multicolumn{2}{|c|}{$15.3(17.4)$} & $<0.001$ \\
\hline Male:female ratio & \multicolumn{2}{|c|}{1.4} & \multicolumn{2}{|c|}{1.1} & 0.258 \\
\hline \multicolumn{6}{|l|}{ Signs and symptoms } \\
\hline Abdominal pain & 166 & 48.7 & 31 & 37.3 & 0.063 \\
\hline Nausea and vomiting & 256 & 75.1 & 57 & 68.7 & 0.234 \\
\hline Loss of appetite & 261 & 76.5 & 58 & 69.9 & 0.207 \\
\hline Fever & 294 & 86.2 & 62 & 74.7 & 0.010 \\
\hline Defecation $\geq 6$ times per 24 hours & 210 & 61.6 & 60 & 72.3 & 0.069 \\
\hline Bloody stool & 80 & 23.5 & 21 & 25.3 & 0.724 \\
\hline Mucoid stool & 13 & 3.8 & 6 & 7.2 & 0.177 \\
\hline \multicolumn{6}{|l|}{ Clinical history } \\
\hline Concurrent diseases present ${ }^{a}$ & 73 & 21.4 & 17 & 20.5 & 0.853 \\
\hline History of previous persistent diarrhoea & 18 & 5.3 & 7 & 8.4 & 0.298 \\
\hline History of major diet change & 36 & 10.6 & 17 & 20.5 & 0.014 \\
\hline Antibiotics & 284 & 83.3 & 78 & 94.0 & 0.013 \\
\hline Anticholinergic drugs & 18 & 5.3 & 10 & 12.0 & 0.026 \\
\hline Breastfed $^{b}$ & 144 & 65.5 & 46 & 64.8 & 0.513 \\
\hline
\end{tabular}

anfections, immunodeficiency and gastrointestinal disorders.

${ }^{b}$ Data for children aged $<2$ years only $(\mathrm{n}=220$ for acute diarrhoea and $\mathrm{n}=71$ for persistent diarrhoea group). $S D=$ standard deviation . 
Antibiotic and anticholinergic drug use during the acute phase was significantly higher in the persistent diarrhoea than the acute diarrhoea group (Table 1). A summary of medication administered during the acute phase of the diarrhoeal disease (including drugs administered in the hospital before and after admission by parents or other physicians) is shown in Figure 1.

The mean of weight-for-age $z$-score was similar in both groups: -0.76 (SD 1.54 ) in acute diarrhoea and -0.77 (SD $1.28)$ in persistent diarrhoea patients.

In the age group $<4$ months, 20 out of $36(55.6 \%)$ were exclusively breastfed and in the age group $<6$ months 26 out of $73(35.6 \%)$ were exclusively breastfed. The proportion of exclusively breastfed infants was significantly higher in the persistent diarrhoea than the acute diarrhoea group, analysing only those aged $<2$ years ( $14.5 \%$ versus $4.4 \%, P=0.001)$. There was no difference between the acute and persistent diarrhoea groups in the frequency of breastfed and non-breastfed children (age $<2$ years only).

Two deaths occurred during this study and both were related to the underlying disease of the patient and not to the diarrhoeal disease.

\section{Enteropathogens in stool specimens}

Laboratory testing of stool specimens for enteropathogens gave a positive result in only $42 \%$ of acute and 36\% of persistent diarrhoea cases (Figure 2).

EAEC was the most frequently isolated enteropathogen in both groups. No clear difference in the profile of infection was found between cases of acute and persistent diarrhoea (Table 2). Salmonella spp. was the only pathogen with a significantly higher prevalence in persistent diarrhoea ( $2 / 83$ cases) than acute diarrhoea cases ( $0 / 341$ cases) $(P$ $=0.038)$, although the number of cases was very small.

\section{Discussion}

Due to the fact that this was a hospitalbased study performed in a referral centre, a high frequency of persistent diarrhoea was expected. The prevalence of persistent diarrhoea (19.6\% overall and $21.8 \%$ in children aged $<5$ years) was higher than that reported in a study from west of Islamic Republic of Iran (7.7\%). This may be because of the difference in admission status of the cases (inpatient versus outpatients). The rate of persistent diarrhoea is lower than that from a hospital-based study in Brazil (56.9\%) [8] but higher than in Nigeria (11.7\%) [9]. Age is a major determinant in the development of persistent diarrhoea. Our results showed that diarrhoea was more likely to be persistent in younger children and this is consistent with the findings of previous studies in Kenya, Peru, Egypt and Guatemala [2,10-13].

Comparing some related symptoms and characteristics of the diarrhoeal disease, we found that the illness was similar in severity in persistent diarrhoea and acute diarrhoea cases. Studies from Nigeria and Egypt have reported similar findings $[9,12]$. A major dietary change (such as introducing complementary food or animal milk to the child) 2 weeks prior to admission was more common in persistent diarrhoea than the acute diarrhoea cases. This may underscore the role of non-infectious causes, especially allergies, in the development of persistent

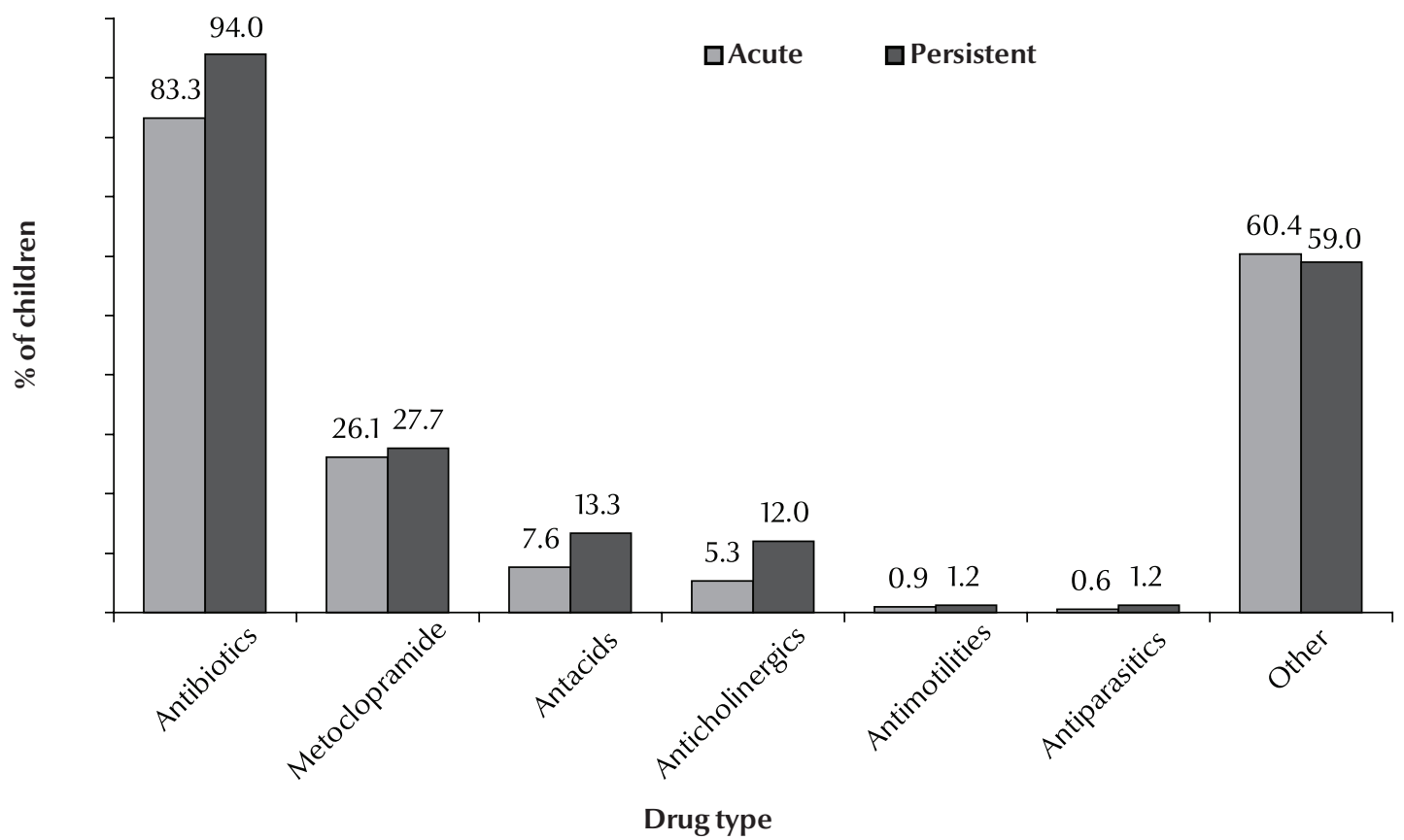

Figure 1 Frequency of drug administration to children hospitalized with acute $(n=341)$ and persistent diarrhoea $(n=83)$ before, during or after hospitalization (any time during acute phase of the diarrhoeal episode) 


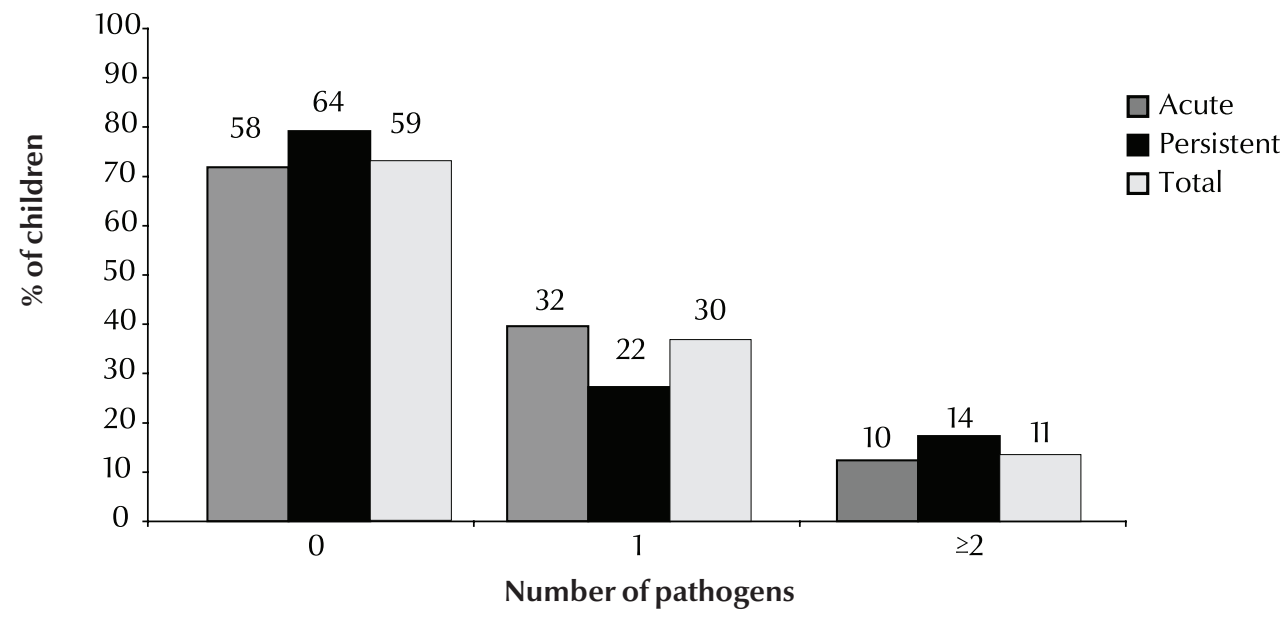

Figure 2 Number of pathogens isolated from stool specimens of children hospitalized with acute $(n=341)$ and persistent diarrhoea $(n=83)$

diarrhoea. The frequency of exclusive breastfeeding was not very high among the children, so most of them were already exposed to foodborne infections. A diet change such as introducing animal milk or complementary food to an infant who is not exclusive breastfed or changing formula brand may indicate other causes of diarrhoea. Supported by the results of previous studies, we noticed that antibiotic and anticholinergic drug use during the initial days of a diarrhoeal episode was associated with longer duration of the disease [14-17].

Enteropathogens were identified in only $42 \%$ of acute and $36 \%$ of persistent diarrhoea cases. There are several reasons for this relatively low rate. First, we did not exclude patients treated with antibiotics prior to stool examination, which might result in negative bacterial growth. Secondly, we did not test the specimens for some bacterial enteropathogens-e.g. Clostridium difficile, Aeromonas spp. and Campylobacter spp.- - or for any viral enteropathogens. Thirdly, a proportion of diarrhoeal episodes may be due to non-infectious causes such as food allergies or chronic non-specific diarrhoea of childhood, as noted by Vernacchio et al. [18].

Several studies from Bangladesh, India and Brazil have recognized EAEC as an important pathogen in developing persistent diarrhoea [19-22]. We also found it as the most prevalent pathogen in cases of both acute and persistent diarrhoea albeit with no significant difference between the 2 groups.Surprisingly, protozoa,especially Cryptosporidium spp. which is presumed to be one of the main etiological agents of persistent diarrhoea, was not associated with prolonged diarrhoea in our study $[2,17,23]$. Salmonella spp. was the only pathogen with a significantly higher prevalence in persistent diarrhoea than acute diarrhoea cases in this study, although the numbers were very small.

When assessing malnutrition, a demonstrated risk factors for persistent diarrhoea $[9,24,25]$, we found no difference between the 2 groups.

Breastfeeding is a protective factor for persistent diarrhoea, as indicated in several studies $[5,7,23]$, but in our study

\begin{tabular}{|c|c|c|c|c|c|}
\hline \multirow[t]{2}{*}{ Enteropathogen } & \multicolumn{2}{|c|}{ Acute diarrhoea $(n=341)$} & \multicolumn{2}{|c|}{ Persistent diarrhoea $(n=83)$} & \multirow[t]{2}{*}{$P$-value } \\
\hline & No. & $\%$ & No. & $\%$ & \\
\hline Giardia lamblia trophozoite & 1 & 0.3 & 1 & 1.2 & 0.35 \\
\hline Cryptosporidium spp. & 6 & 1.8 & 1 & 1.2 & 1.00 \\
\hline Blastocystis hominis & 13 & 3.8 & 1 & 1.2 & 0.32 \\
\hline Salmonella spp. & 0 & 0.0 & 2 & 2.4 & 0.04 \\
\hline Shigella spp. & 7 & 2.1 & 2 & 2.4 & 0.69 \\
\hline Enteroaggregative Escherichia coli (EAEC) & 60 & 17.6 & 15 & 18.1 & 0.92 \\
\hline Enteropathogenic E. coli (EPEC) & 18 & 5.3 & 5 & 6.0 & 0.79 \\
\hline Shiga-toxin-producing E. coli (STEC) & 25 & 7.3 & 6 & 7.2 & 0.97 \\
\hline Enterotoxigenic E. coli (ETEC) & 21 & 6.2 & 5 & 6.0 & 0.96 \\
\hline Enteroinvasive $E$. coli (EIEC) & 31 & 9.1 & 5 & 6.0 & 0.37 \\
\hline
\end{tabular}


the frequency of breastfeeding in children $<2$ years of age was similar in the acute and persistent diarrhoea groups. However, it should be mentioned that the proportion of exclusively breastfed infants was significantly higher in the persistent diarrhoea than the acute diarrhoea group ( $14.5 \%$ versus $4.4 \%)$. We also observed that only $55.6 \%$ of infants under 4 months and $35.6 \%$ under 6 months of age were exclusively breastfed. This, along with the fact that mothers tend to discontinue breastfeeding during a diarrhoeal episode, implies the need for an extended public health education programme for diarrhoeal disease in the Islamic Republic of Iran.

Follow-up of the children showed no deaths associated with acute or persistent diarrhoea. This may be a result of good hospital care especially in the case of rehydration and nutritional care.

This study presents some data about persistent diarrhoea in a hospital setting and although the findings are not representative of the community, they clarify some aspects of persistent diarrhoea in Iranian children. Persistent diarrhoea seems to be a benign disease in the Iranian paediatric population. Young age, antibiotic and anticholinergic drug use, a history of a significant diet change 2 weeks before the onset of diarrhoea and presence of Salmonella spp. are some factors that may be involved in persistent diarrhoea.

\section{Acknowledgements}

The authors wish to thank Ms F. Mola, Ms M. Ghafoori, Dr B. Noorinayer, Dr M.A. Pourhoseingholi and Dr F. Firoozi for their kind assistance. This study was funded by the Research Center for Gastroenterology and Liver Diseases, Shahid Beheshti University.

\section{References}

1. Black RE, Morris SS, Bryce J. Where and why are 10 million children dying every year? Lancet, 2003, 361:2226-2234.

2. Persistent diarrhoea in children in developing countries: memorandum from a WHO meeting. Bulletin of the World Health Organization, 1988, 66:709-717.

3. Bhutta ZA et al. Persistent and chronic diarrhoea and malabsorption: Working Group report of the second World Congress of Pediatric Gastroenterology, Hepatology, and Nutrition. Journal of pediatric gastroenterology and nutrition, 2004, 39(Suppl. 2):S711-716.

4. Ochoa TJ, Salazar-Lindo E, Cleary TG. Management of children with infection-associated persistent diarrhoea. Seminars in Pediatric Infectious Diseases, 2004, 15:229-236.

5. Batebi A et al. A study of effective factors on persistent diarrhoea in under five years old children. Iranian Journal of Public Health, 1997, 26:31-40.

6. Honarpisheh A et al. A study on the relationship between malnutrition and persistent diarrhea. Journal of Kashan University of Medical Sciences, 1997, 1(1):29-33.

7. Pourahmadi S, Vakili R. Predisposing factors in persistent diarrhoea. Iranian Journal of Pediatrics, 1999, 42:20-24.

8. Lins MD, Silva GA. Doenca diarreica em criancas hospitalizadas - importancia da diarreia persistente [Diarrheal disease in hospitalized children-importance of the persistent diarrhoea]. Jornal de Pediatria, 2000, 76:37-43.

9. Sodeinde $\mathrm{O}$ et al. Persistent diarrhoea in Nigerian children aged less than five years: a hospital-based study. Journal of Diarrhoeal Diseases Research, 1997, 15:155-160.

10. Mbori-Ngacha DA et al. Prevalence of persistent diarrhoea in children aged 3-36 months at the Kenyatta National Hospital, Nairobi, Kenya. East African Medical Journal, 1995, 72:711-714.

11. Lanata CF et al. Epidemiologic, clinical, and laboratory characteristics of acute vs. persistent diarrhoea in periurban Lima, Peru. Journal of Pediatric Gastroenterology and Nutrition, 1991, 12:82-98.

12. Mahmud MA et al. Sociodemographic, environmental and clinical risk factors for developing persistent diarrhoea among infants in a rural community of Egypt. Journal of health, population, and nutrition, 2001, 19:313-319.
13. Cruz JR et al. Epidemiology of persistent diarrhoea among Guatemalan rural children. Acta Paediatrica, supplement, 1992, 381:22-26.

14. Karim AS et al. Risk factors of persistent diarrhoea in children below five years of age. Indian Journal of Gastroenterology, 2001, 20:59-61

15. Shahid NS et al. Risk factors for persistent diarrhoea. British Medical Journal, 1988, 297:1036-1038.

16. Araya $\mathrm{M}$ et al. Persistent diarrhoea in the community. Characteristics and risk factors. Acta Paediatrica, 1991, 80:181-189.

17. Sodemann $\mathrm{M}$ et al. Episode-specific risk factors for progression of acute diarrhoea to persistent diarrhoea in West African children. Transactions of the Royal Society of Tropical Medicine and Hygiene, 1999, 93:65-68.

18. Vernacchio $L$ et al. Characteristics of persistent diarrhoea in a community-based cohort of young US children. Journal of Pediatric Gastroenterology and Nutrition, 2006, 43:52-58.

19. Henry FJ et al. Epidemiology of persistent diarrhoea and etiologic agents in Mirzapur, Bangladesh. Acta Paediatrica, supplement, 1992, 381:27-31.

20. Fang GD et al. Etiology and epidemiology of persistent diarrhoea in northeastern Brazil: a hospital-based, prospective, case-control study. Journal of Pediatric Gastroenterology and Nutrition, 1995, 21:137-144.

21. Bhatnagar $\mathrm{S}$ et al. Enteroaggregative Escherichia coli may be a new pathogen causing acute and persistent diarrhoea. Scandinavian Journal of Infectious Diseases, 1993, 25:579-583.

22. Bardhan PK et al. Small bowel and fecal microbiology in children suffering from persistent diarrhoea in Bangladesh. Journal of Pediatric Gastroenterology and Nutrition, 1998, 26:9-15.

23. Lima AA et al. Persistent diarrhoea signals a critical period of increased diarrhoea burdens and nutritional shortfalls: a prospective cohort study among children in northeastern Brazil. Journal of Infectious Diseases, 2000, 181:1643-1651.

24. Bhandari $\mathrm{N}$ et al. Association of antecedent malnutrition with persistent diarrhoea: a case-control study. British Medical Journal, 1989, 298:1284-1287.

25. Black RE, Brown KH, Becker S. Malnutrition is a determining factor in diarrhoea I duration, but not incidence, among young children in a longitudinal study in rural Bangladesh. American Journal of Clinical Nutrition, 1984, 39:87-94. 